\title{
Variation of platelet parameters in preterm neonates
}

\author{
Chandrakala P., Krithika G. S.* \\ Department of Pediatrics, Kempegowda Institute of Medical Sciences, Bengaluru, Karnataka, India
}

\author{
Received: 11 March 2021 \\ Revised: 09 April 2021 \\ Accepted: 16 April 2021 \\ *Correspondence: \\ Dr. Krithika G. S., \\ E-mail: kritika.gs@gmail.com
}

Copyright: $@$ the author(s), publisher and licensee Medip Academy. This is an open-access article distributed under the terms of the Creative Commons Attribution Non-Commercial License, which permits unrestricted non-commercial use, distribution, and reproduction in any medium, provided the original work is properly cited.

\begin{abstract}
Background: Platelets play a crucial role in hemostasis and phagocytosis. These functions of platelets are acquired gradually from foetal life to infant life. Larger, immature platelets are more reactive and hence platelet mass indices may be indicative of the thrombotic potential of platelets.

Methods: This study was conducted in Kempegowda institute of medical sciences and research centre attached hospital in Bengaluru, Karnataka, India between January, 2019 and July, 2020. Platelet count, mean platelet volume (MPV), platelet distribution width (PDW) was obtained from automated analyzer reports (SYSMEX XT 1800i). The statistical association between the gestational age, birth weight and gender of preterm and their platelet parameters, was then assessed.

Results: In this study, the effect of gestational age, birth weight and gender on platelet parameters was studied. A significant correlation between PDW (platelet distribution width), MPV (mean platelet volume) and gestational age was found. It was found that with increasing gestational age, both PDW and MPV decreased. With respect to birth weight, the mean, median PDW significantly decreased with increasing birth weight. None of the platelet parameters were different between male and female preterm neonates.

Conclusions: There still remains a paucity of studies regarding the correlation between platelet mass indices and gestational age and birth weight. While some studies show positive correlation, some studies show no correlation and this study shows negative correlation. Hence, this calls for more studies, with larger sample sizes, to be undertaken.
\end{abstract}

Keywords: Platelet, PDW, MPV, Preterm, Gestational age, Birth weight

\section{INTRODUCTION}

Platelets play a crucial role in hemostasis. They are also essential in neonates, for vessel wall integrity and immunity. From foetal life to infancy, these functions of platelets gradually gain maturity. ${ }^{1}$ Hemostasis is less effective in neonates than in adults. ${ }^{2}$ Platelet counts were found to be lower in preterm neonates and low birth weight babies. ${ }^{3}$ The platelet count alone does not completely determine the thrombotic potential of blood. The platelet maturity is indicated by platelet size and this is measured by platelet mass parameters like, mean platelet volume (MPV), plateletcrit (PCT), and platelet distribution width (PDW). Platelet mass parameters are directly proportional to the thrombotic potential of the platelets as larger the platelets have a greater reactivity. This, can be used to predict possible disease state, earlier.

A total $8-35 \%$ of all newborns admitted to the neonatal intensive care unit (NICU) develop thrombocytopenia during their stay in the NICU. ${ }^{4-6}$ This pre-term may develop several morbidities like respiratory distress syndrome, bronchopulmonary dysplasia, neonatal sepsis, necrotizing enterocolitis, intraventricular hemorrhage, retinopathy of prematurity. A knowledge of these platelet parameters helps to predict the occurrence of these morbidities. ${ }^{7,8}$ It is therefore evident that pre-terms who have lower platelet count and more immature platelets are more prone to morbidities. 
The objective of study was to find a possible association and correlation between birth parameters like gestational age, birth weight and gender and platelet parameters.

\section{METHODS}

This was a prospective study conducted in Kempegowda institute of medical sciences and research center, Bengaluru, Karnataka, India between January, 2019 and July, 2020. The neonates admitted in the NICU of department of pediatrics were the subjects of the study. All neonates with gestational age $<37$ weeks with no obvious external anomalies and who survived beyond the third day of life were included in the study. Neonates with insufficient data regarding platelet parameters on day1 were excluded from the study.

After obtaining approval and clearance from the institutional ethics committee, the patients fulfilling the inclusion criteria were enrolled for the study after obtaining informed consent. Data was entered into case record form with follow up chart. The gestational age was determined by modified Ballard's score.

Platelet count, mean platelet volume (MPV), platelet distribution width (PDW) and platelet mass index (PMI) were evaluated at birth, and repeated at 48-72 hours of life on $2 \mathrm{ml}$ of venous blood collected in EDTA vial. Platelet count, mean platelet volume and Platelet distribution width was obtained from automated analyzer reports (SYSMEX XT 1800i).

The statistical association between the gestational age, birth weight and gender of preterm and their platelet parameters, was then assessed.

\section{RESULTS}

The hundred pre-term neonates admitted to NICU were studied. Their platelet parameters on day 1 was noted. These platelet parameters were correlated with neonatal factors like gestational age, birth weight and gender.

The platelet parameters like platelet count, PDW (in fl), MPV (in fl), PCT (\%), P-LCR and PMI were evaluated in pre-terms <32 weeks, 32-34 weeks and neonates >34 weeks and significant differences were noted.

\section{Gestational age}

The platelet parameters like platelet count, PDW (in fl), MPV (in fl), PCT (\%), P-LCR and PMI were evaluated in pre-terms <32 weeks, 32-34 weeks and neonates >34 weeks and significant differences were noted.

Gestational age (weeks) was not normally distributed (Shapiro-Wilk test: $\mathrm{p}=<0.001$ ).

The mean (SD) of gestational age (weeks) was 33.95 (1.91). The median (IQR) of gestational age (weeks) was 34.00 (32-36). The gestational age (weeks) ranged from 29-37.

It was noticed in data from Table 1 that PDW and MPV on both day 1 was significantly different between the two groups. $\mathrm{P}<0.05$ was considered significant as depicted in Table 1.

\section{PDW and gestational age}

It was observed that the mean, median and range of PDW decreased with increasing gestational age, on both day 1 , as in Table 2.

The variable PDW (fl) was not normally distributed in the 3 subgroups of the variable gestational age. Thus, non-parametric tests (Kruskal Wallis test) were used to make group comparisons.

Table 1: Association between gestational age and parameters.

\begin{tabular}{|c|c|c|c|c|}
\hline \multirow{2}{*}{ Parameters (day 1) } & \multicolumn{3}{|c|}{ Gestational age (weeks) } & \multirow{2}{*}{ P value } \\
\hline & $<32(\mathrm{n}=12)$ & $32-34(n=44)$ & $>34(n=44)$ & \\
\hline Platelet count (Lac/cu.mm) & $2.10 \pm 0.76$ & $2.08 \pm 0.63$ & $2.20 \pm 0.92$ & 0.821 \\
\hline PDW (fl) & $18.56 \pm 4.36$ & $15.21 \pm 4.39$ & $12.81 \pm 3.22$ & $<0.001$ \\
\hline MPV (fl) & $12.15 \pm 1.80$ & $10.85 \pm 2.27$ & $10.50 \pm 1.13$ & 0.018 \\
\hline PCT (\%) & $0.21 \pm 0.03$ & $0.20 \pm 0.03$ & $0.21 \pm 0.04$ & 0.743 \\
\hline P-LCR & $28.82 \pm 3.93$ & $26.13 \pm 4.31$ & $25.58 \pm 4.76$ & 0.092 \\
\hline
\end{tabular}

Significant at $\mathrm{p}<0.05,1$ : Kruskal Wallis test

Table 2: Day 1, comparison of the 3 subgroups of the variable gestational age in terms of PDW (fl), (n=100).

\begin{tabular}{|c|c|c|c|c|c|}
\hline \multirow[t]{2}{*}{ PDW (fl) } & \multicolumn{3}{|c|}{ Gestational age (weeks) } & \multicolumn{2}{|c|}{$\begin{array}{l}\text { Kruskal Wallis } \\
\text { test }\end{array}$} \\
\hline & $<32$ & $32-34$ & $>34$ & $\chi^{2}$ & $P$ value \\
\hline Mean (SD) & $18.56(4.36)$ & $15.21(4.39)$ & $12.81(3.22)$ & \multirow{3}{*}{$\begin{array}{l}15.91 \\
9\end{array}$} & \multirow{3}{*}{$<0.001$} \\
\hline Median (IQR) & $18.6(16.1-21.82)$ & $15.25(11.4-18.18)$ & $11.55(10.57-13.53)$ & & \\
\hline Range & $11.2-24.5$ & $9.9-24.1$ & $9.7-24.1$ & & \\
\hline
\end{tabular}


The correlation between PDW and gestational age was then studied.

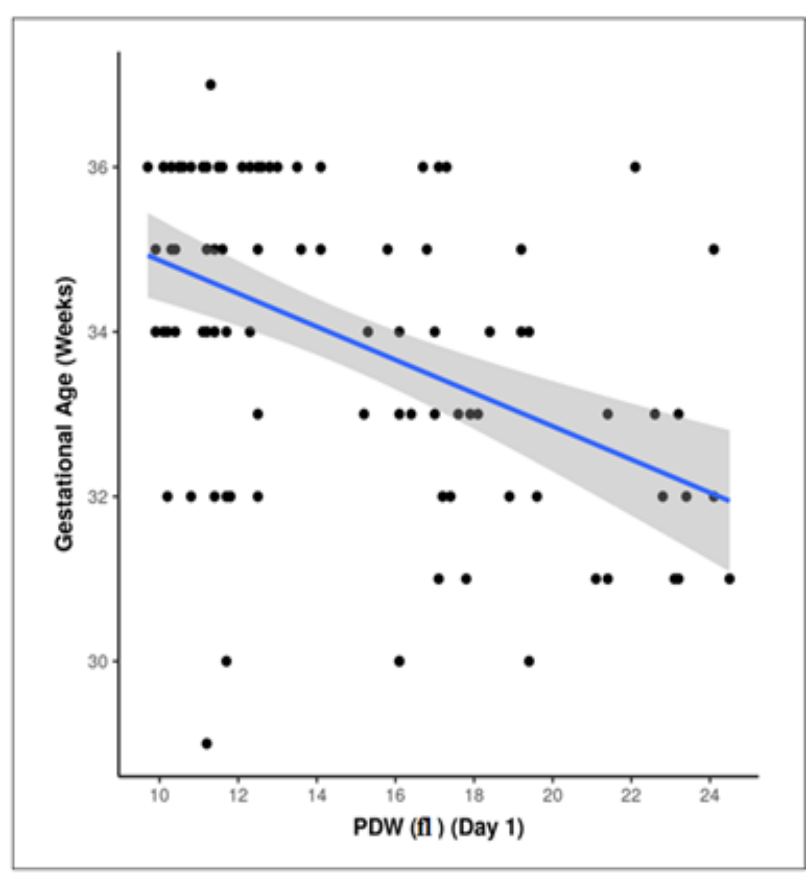

Figure 1: Correlation between gestational age and PDW.

Non-parametric tests (Spearman correlation) were used to explore the correlation between the two variables, as at least one of the variables was not normally distributed as represented in Figure 1.

The spearman correlation coefficient was -0.450 with a $\mathrm{p}=<0.001$.

On day 1 , there was a moderate negative correlation between PDW (fl) and gestational age (weeks), and this correlation was statistically significant (rho $=-0.45$, $\mathrm{p}=<0.001)$.

For every 1 unit increase in PDW (\%) (fl), the gestational age (weeks) decreases by 0.20 units. Conversely, for every week increase in gestational age, the PDW (fl) decreases by 1.02 units.

\section{MPV and gestational age}

It was observed that the mean platelet volume decreased significantly with increasing gestational age while the median was lower in neonates $<32$ weeks and similar in neonates $>32$ weeks. The range of mean platelet volume did not show significant difference across the groups. This is depicted in Table 3.

The variable mean platelet volume (fl) was not normally distributed in the 3 subgroups of the variable gestational age. Thus, non-parametric tests (Kruskal Wallis test) were used to make group comparisons.
Table 3: Day 1, comparison of the 3 subgroups of the variable gestational age in terms of $\operatorname{MPV}(\mathbf{f l}),(n=100)$.

\begin{tabular}{|c|c|c|c|c|c|}
\hline \multirow{2}{*}{$\begin{array}{l}\text { MPV } \\
\text { (fi) }\end{array}$} & \multicolumn{3}{|c|}{ Gestational age (Weeks) } & \multicolumn{2}{|c|}{$\begin{array}{l}\text { Kruskal } \\
\text { Wallis test }\end{array}$} \\
\hline & $<32$ & $32-34$ & $>34$ & $\chi^{2}$ & $\begin{array}{l}P \\
\text { value }\end{array}$ \\
\hline $\begin{array}{l}\text { Mean } \\
\text { (SD) }\end{array}$ & $\begin{array}{l}12.15 \\
(1.80)\end{array}$ & $\begin{array}{l}10.85 \\
(2.27)\end{array}$ & $\begin{array}{l}10.50 \\
(1.13)\end{array}$ & \multirow{3}{*}{8.034} & \multirow{3}{*}{0.018} \\
\hline $\begin{array}{l}\text { Median } \\
\text { (IQR) }\end{array}$ & $\begin{array}{l}11.75 \\
(10.75- \\
14.12)\end{array}$ & $\begin{array}{l}10.75 \\
(9.78- \\
11.88)\end{array}$ & $\begin{array}{l}10.25 \\
(9.78- \\
11.22)\end{array}$ & & \\
\hline Range & $\begin{array}{l}9.8- \\
14.4\end{array}$ & $\begin{array}{l}10.59- \\
16\end{array}$ & $\begin{array}{l}9- \\
13.6\end{array}$ & & \\
\hline
\end{tabular}

The correlation between MPV and platelet parameters was then studied.

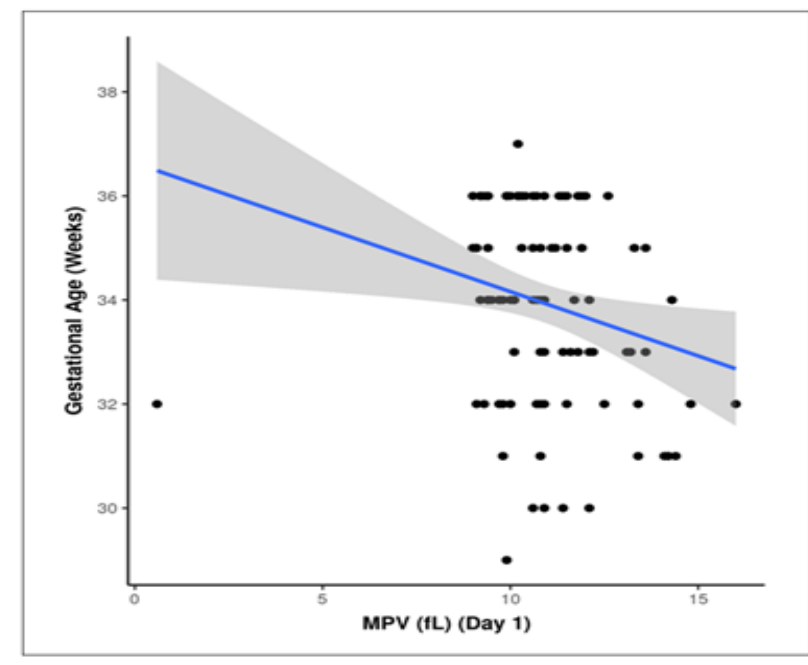

Figure 2: Correlation between gestational age and MPV.

A Spearman correlation coefficient of -0.290 with a $\mathrm{p}=0.003$ was observed as in Figure 2 .

On day 1 , there was a weak negative correlation between MPV (fl) and gestational age (weeks), and this correlation was statistically significant (rho=-0.29, $\mathrm{p}=0.003$ ).

For every 1 unit increase in MPV (fl), the gestational age (weeks) decreases by 0.25 units. Conversely, for every week increase in gestational age, the MPV (fl) decreases by 0.23 units.

\section{Birth weight}

Birth weight $(\mathrm{kg})$ was not normally distributed (ShapiroWilk test: $\mathrm{p}=0.015)$.

The mean (SD) of birth weight $(\mathrm{kg})$ was $1.83(0.49)$. The median (IQR) of birth weight $(\mathrm{kg})$ was $1.83(1.4-2.13)$. The birth weight $(\mathrm{kg})$ ranged from 0.88-2.9. 
It was noted that the platelet count and PDW were significantly different between the groups on both day 1 . This is depicted in Table 4.

\section{Platelet count and birth weight}

It was observed that the mean platelet count increased significantly with increasing birth weight. The median platelet count was found to increase with increasing birth weight up to $1.5 \mathrm{~kg}$. The median birth weight remained similar in neonates $>1.5 \mathrm{~kg}$. This is depicted in Table 5 .

The variable platelet count (Lac/cu.mm) was not normally distributed in the 4 subgroups of the variable birth weight. Thus, non-parametric tests (Kruskal Wallis test) were used to make group comparisons.

The correlation between the platelet count and birth weight was then studied

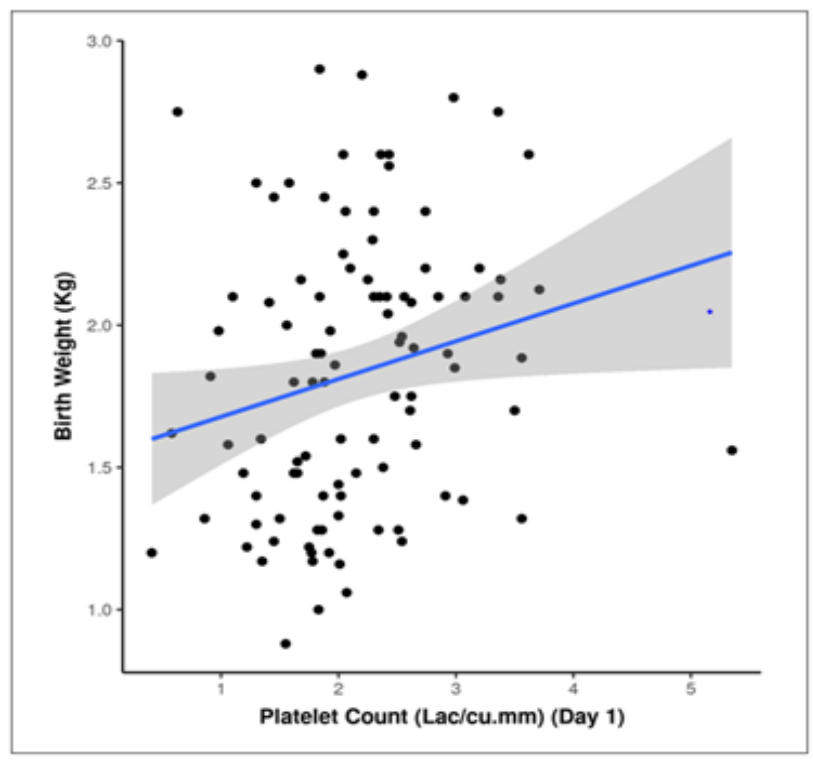

Figure 3: Correlation between gestational age and PDW.

A Spearman correlation coefficient of 0.290 with a $\mathrm{p}=0.004$ was observed as in table Figure 3 .

On day 1 , there was a weak positive correlation between platelet count (Lac/cu.mmand birth weight $(\mathrm{kg})$, and this correlation was statistically significant $\quad(\mathrm{rho}=0.29$, $\mathrm{p}=0.004)$.

For every 1 unit increase in platelet count (Lac/cu.mm), the birth weight $(\mathrm{kg})$ increases by 0.13 units. Conversely, for every kilogram increase in birth weight, the platelet count increases by 0.34 lakh/cu.mm.

\section{PDW and birth weight}

The mean, median PDW significantly decreased with increasing birth weight as shown in Table 6 .

The variable PDW (fl) was not normally distributed in the 4 subgroups of the variable birth weight. Thus, nonparametric tests (Kruskal Wallis test) were used to make group comparisons.

Correlation between PDW and birth weight then studied.

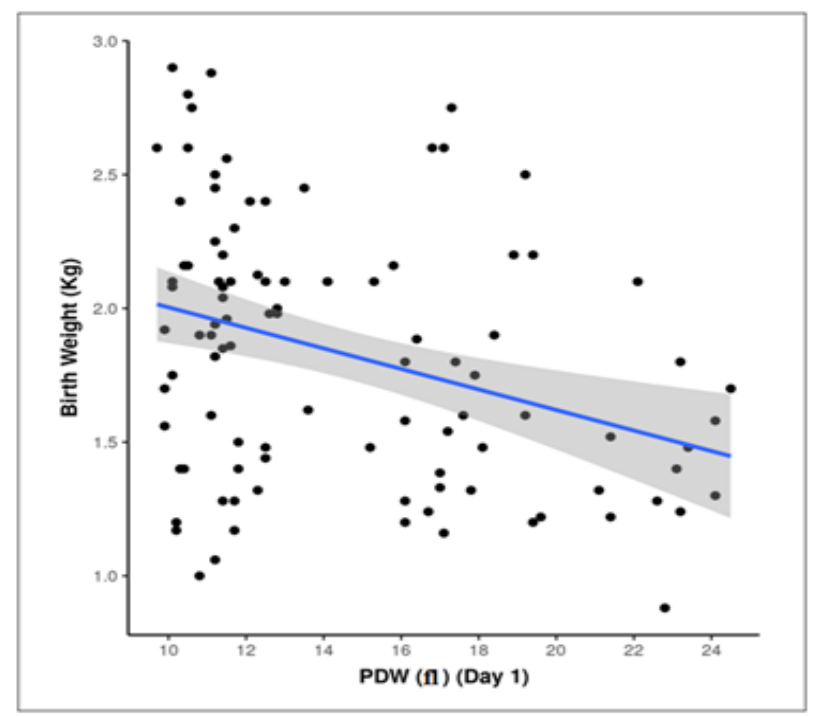

Figure 4: Correlation between gestational age and PDW.

Non-parametric tests (Spearman correlation) were used to explore the correlation between the two variables, as at least one of the variables was not normally distributed.

A Spearman correlation coefficient of -0.300 with a $\mathrm{p}=0.003$ was observed as in Figure 4 .

Table 4: Association between birth weight and parameters.

\begin{tabular}{|c|c|c|c|c|c|}
\hline \multirow{2}{*}{ Parameters (day 1) } & \multicolumn{4}{|c|}{ Birth weight (kg) } & \multirow{2}{*}{ P value } \\
\hline & $<1(n=1)$ & $1-1.5(n=31)$ & $1.5-2.5(n=56)$ & $\geq 2.5(n=12)$ & \\
\hline $\begin{array}{l}\text { Platelet count } \\
\text { (Lac/cu.mm) }\end{array}$ & $1.55 \pm 0$ & $1.86 \pm 0.63$ & $2.28 \pm 0.81$ & $2.23 \pm 0.85$ & 0.036 \\
\hline PDW (\%) & $22.80 \pm 0$ & $16.00 \pm 4.67$ & $13.95 \pm 3.95$ & $12.97 \pm 3.50$ & 0.038 \\
\hline MPV (fl) & $10.80 \pm 0$ & $11.10 \pm 2.70$ & $10.84 \pm 1.32$ & $10.29 \pm 1.23$ & 0.278 \\
\hline PCT (\%) & $0.15 \pm 0$ & $0.20 \pm 0.03$ & $0.21 \pm 0.03$ & $0.20 \pm 0.04$ & 0.075 \\
\hline P-LCR & $28.60 \pm 0$ & $26.72 \pm 4.08$ & $26.48 \pm 4.90$ & 23.423 .17 & 0.102 \\
\hline
\end{tabular}

Significant at $\mathrm{p}<0.05,1$ : Kruskal Wallis test 
Table 5: Day 1, comparison of the 4 subgroups of the variable birth weight in terms of platelet count, $(\mathrm{n}=100)$.

\begin{tabular}{|c|c|c|c|c|c|c|}
\hline \multirow{2}{*}{$\begin{array}{l}\text { Platelet count } \\
\text { (Lac/cu.mm) }\end{array}$} & \multicolumn{4}{|c|}{ Birth weight (kg) } & \multicolumn{2}{|c|}{ Kruskal Wallis test } \\
\hline & $<1$ & $1-1.5$ & $1.5-2.5$ & $\geq 2.5$ & $\chi^{2}$ & $P$ value \\
\hline Mean (SD) & 1.55 (NA) & $1.86(0.63)$ & $2.28(0.81)$ & $2.23(0.85)$ & \multirow{3}{*}{8.546} & \multirow{3}{*}{0.036} \\
\hline Median (IQR) & $1.55(1.55-1.55)$ & $1.83(1.48-2.04)$ & $2.3(1.8-2.64)$ & $2.28(1.78-2.57)$ & & \\
\hline Range & $1.55-1.55$ & $0.41-3.56$ & $0.58-5.35$ & $0.63-3.62$ & & \\
\hline
\end{tabular}

Table 6: Day 1, comparison of the 4 subgroups of the variable birth weight in terms of PDW (fl), (n=100).

\begin{tabular}{|c|c|c|c|c|c|c|}
\hline \multirow{2}{*}{ PDW (fl) } & \multicolumn{4}{|c|}{ Birth weight (kg) } & \multicolumn{2}{|c|}{ Kruskal Wallis test } \\
\hline & $<1$ & $1-1.5$ & $1.5-2.5$ & $\geq 2.5$ & $\chi^{2}$ & P value \\
\hline Mean (SD) & 22.80 (NA) & $16.00(4.67)$ & $13.95(3.95)$ & $12.97(3.50)$ & \multirow{3}{*}{8.454} & \multirow{3}{*}{0.038} \\
\hline Median (IQR) & $22.8(22.8-22.8)$ & $16.1(11.7-19.5)$ & $12.4(11.2-16.1)$ & $11.15(10.5-16.8)$ & & \\
\hline Range & $22.8-22.8$ & $10.2-24.1$ & $9.9-24.5$ & $9.7-19.2$ & & \\
\hline
\end{tabular}

On day 1 , there was a weak negative correlation between PDW (fl) and birth weight $(\mathrm{kg})$, and this correlation was statistically significant (rho=-0.3, p=0.003).

For every 1 unit increase in PDW (fl), the birth weight (kg) decreases by 0.04 units. Conversely, for every kilogram increase in birth weight, the PDW decreases by $2.98 \mathrm{fl}$.

\section{Gender}

Sixty percentage of the neonates were male babies while $40.0 \%$ were female babies.

The mean platelet count (lakh/cumm) was $2.11 \pm 0.73$ in males and $2.18 \pm 0.86$ in females $(\mathrm{p}=0.746)$, PDW (\%) was $14.70 \pm 4.48$ in males and $14.34 \pm 4.06$ in females $(\mathrm{p}=0.908), \operatorname{MPV}$ (fl) was $10.85 \pm 2.13$ in males and $10.85 \pm 1.34$ in females $(\mathrm{p}=0.986)$, PCT $(\%)$ was $0.2 \pm 0.04$ in males and $0.20 \pm 0.03$ in females $(\mathrm{p}=0.475)$, P-LCR was $25.87 \pm 4.54$ in males and $26.71 \pm 4.56$ in females $(p=0.37)$.

None of the platelet parameters were different between male and female preterm neonates.

\section{DISCUSSION}

Platelets have functions such as haemostasis and wound healing. Active platelets have been observed as early as 12 weeks in the blood of foetus. ${ }^{9}$ This shows that thrombosis is a phenomenon present in foetal life itself.

Several studies have indicated that platelet counts increased with increasing foetal life. A study by SE Wiedmeier et al. showed that for each week of gestational age, the platelet counts increased 2089 microlitre $^{-1}$ $(\mathrm{p}=0.000) .{ }^{10} \mathrm{~A}$ significant difference was seen between neonates born less than 35 weeks and after with platelet counts being much less in neonates less than 35 weeks. A significant change was not observed with MPV. In another study by Van den Hof and Nicolaides, platelet count increased from a mean of 187000 microlitre $^{-1}$ at 15 weeks to 274000 microlitre ${ }^{-1} 40$ weeks. ${ }^{11}$ Certain other studies reported no significant differences. ${ }^{12-14}$ In a study

by McPherson et al, the mean platelet count of neonates born early preterm was found to be much lesser than late preterm and term babies. ${ }^{15}$ Therefore, conflicting data regarding the association between platelet count and gestational age exist.

While several studies regarding the association between platelet count and gestational age are present, this is not so with regard to platelet mass parameters and gestational age. Patrick and Lazarchick studied mean platelet volume and found that it was higher in term infants than in preterms. ${ }^{16}$ In contrast to this, a study by Arad et al showed no difference in mean platelet volume between neonates born preterm and $<2 \mathrm{~kg}$ and term neonates. ${ }^{17}$

In this study, the effect of gestational age, birth weight and gender on platelet parameters was studied. It was observed that the mean, median and range of PDW decreased with increasing gestational age. It was observed that the mean MPV decreased significantly with increasing gestational age while the median was lower in neonates $<32$ weeks and similar in neonates $>32$ weeks. The range of MPV did not show significant difference across the groups.

The mean, median PDW significantly decreased with increasing birth weight. It was also observed that, for every kilogram increase in birth weight, the MPV (fl) decreases by $0.93 \mathrm{fl}$.

None of the platelet parameters were different between male and female preterm neonates.

The limitations of this study are that it did not factor the effect of disease states like sepsis and retinopathy of prematurity, on the platelet count and size. Also, it did not study change of platelet size and number over time. 
Megakaryopoiesis or the process of platelet synthesis is initiated by thrombopoietin (Tpo). ${ }^{18}$ Certain studies have shown than thrombopoietin levels in term and pre-terms with normal platelet counts are actually higher than in adults. ${ }^{19-21}$

There is a dearth of studies discussing the association of PDW with gestational age and birth weight. In this study, PDW was observed to decrease with increasing gestational age and possibly implies that platelet maturity was higher in neonates born near term. Decreased PDW without much alteration in MPV may indicate that PDW is a more sensitive index for estimation of changes in platelet size. 22,23

\section{CONCLUSION}

There still remains a paucity of studies regarding the correlation between platelet mass indices and gestational age and birth weight. While some studies show positive correlation, some studies show no correlation and this study shows negative correlation.

Hence, this calls for more studies, with larger sample sizes, to be undertaken. An understanding of the effect and variation of platelet parameters with gestational age will help predict the possibility of neonatal morbidities and also perhaps revise normal values of platelet count and parameters based on prognosis.

Funding: No funding sources

Conflict of interest: None declared

Ethical approval: The study was approved by the Institutional Ethics Committee

\section{REFERENCES}

1. Sola-Visner M. Platelets in the neonatal period: Developmental differences in platelet production, function, and hemostasis and the potential impact of therapies. Hematol Am Soc Hematol Educ Program. 2012;2012:506-11.

2. Israels SJ, Rand ML, Michelson AD. Neonatal platelet function. Semin Thromb Hemost. 2003;29:363-72.

3. Strauss T, Sidlik-Muskatel R, Kenet G. Developmental hemostasis: Primary hemostasis and evaluation of platelet function in neonates. Semin Fetal Neonatal Med. 2011;16:301-4.

4. Mehta P, Vasa R, Neumann L, Karpatkin M. Thrombocytopenia in the high-risk infant. J Pediatr. 1980;97:791-4.

5. Roberts IA, Murray NA. Thrombocytopenia in the newborn. Curr Opin Pediatr. 2003;15:17-23.

6. Aman I, Hassan KA, Ahmad TM. The study of thrombocytopenia in sick neonates. J Coll Physicians Surg Pak. 2004;14:282-5.

7. Hussein NF, Helaly NS, Ghanya EA, Anisb SK. Relationship between Mean Platelet Volume and Bronchopulmonary Dysplasia and Intraventricular
Hemorrhage in Very Low Birth Weight Neonates. J Am Sci. 2012;8:5.

8. Nourripoor S, Tabasizadeh H, Afjehi A, Ghorbani R, Seifhashemi M, Masoudian N. Could mean platelet volume predict developing of bronchopulmonary dysplasia in preterm infants with respiratory distress syndrome? Iran J Neonatol. 2013;4(3):35-41.

9. Kaushansky K, Roth GJ. Platelets and megakaryocytes. In: Greer JP, Forester J, Luken J, Rodgers GM, Paraskevas F, Glader B (eds). Wintrobe's Clinical Hematology. Lippincott Williams and Wilkins: Philadelphia, PA, 2004;60550.

10. Wiedmeier S, Henry E, Sola-Visner M, Christensen R. Platelet reference ranges for neonates, defined using data from over 47000 patients in a multihospital healthcare system. J Perinatol. 2008;29(2):130-6.

11. Van den Hof MC, Nicolaides KH. Platelet count in normal, small, and anemic fetuses. Am J Obstet Gynecol. 1990;162(3):735-9.

12. Forestier F, Daffos F, Galacteros F, Bardakjian J, Rainaut M, Beuzard Y. Hematological values of 163 normal fetuses between 18 and 30 weeks of gestation. Pediatr Res. 1986;20(4):342-6.

13. Forestier F, Daffos F, Catherine N, Renard M, Andreux J-P. Developmental hematopoiesis in normal human fetal blood. Blood. 1991;77(11):23603.

14. Hohlfeld P, Forestier F, Kaplan C, Tissot J-D, Daffos F. Fetal thrombocytopenia: a retrospective survey of 5,194 fetal blood samplings. Blood. 1994;84(6):1851-6.

15. McPherson RJ, Juul S. Patterns of thrombocytosis and thrombocytopenia in hospitalized neonates. J Perinatol. 2005;25(3):166-72.

16. Patrick CH, Lazarchick J. The effect of bacteremia on automated platelet measurements in neonates. Am J Clin Pathol. 1990;93(3):391-4.

17. Arad ID, Alpan G, Sznajderman SD, Eldor A. The mean platelet volume (MPV) in the neonatal period. Am J Perinatol. 1986;3(1):1-3.

18. Kaushansky K. Thrombopoietin. N Engl J Med. 1998;339:746-54.

19. Walka MM, Sonntag J, Dudenhausen JW, Obladen M. Thrombopoietin concentrations in umbilical cord of healthy term newborns is higher than in adult controls. Biol Neonate. 1999;75(1):54-8.

20. Sola MC, Juul SE, Meng YG, Garg S, Sims P, Calhoun DA et al. Thrombopoietin (Tpo) in the fetus and neonate: Tpo concentration in preterm and term neonates, and organ distribution of Tpo and its receptor (c-mpl) during human fetal development. Early Hum Dev. 1999;53(3):239-50.

21. Ishiguro A, Nakahata T, Matsubara K, Hayashi Y, Kato T, Suzuki $\mathrm{Y}$ et al. Age-related changes in thrombopoietin levels. Br J Haematol. 1999;106:8848.

22. Patrick CH, Lazarchick J, Stubbs T, Pittard WB. Mean platelet volume and platelet distribution width 
in the neonate. Am J Pediatr Hematol Oncol. 1987;9:130-2.

23. Park Y, Schoene N, Harris W. Mean platelet volume as an indicator of platelet activation: Methodological issues. Platelets. 2002;13:301-6.
Cite this article as: Chandrakala P, Krithika GS. Variation of platelet parameters in preterm neonates. Int J Contemp Pediatr 2021;8:887-93. 